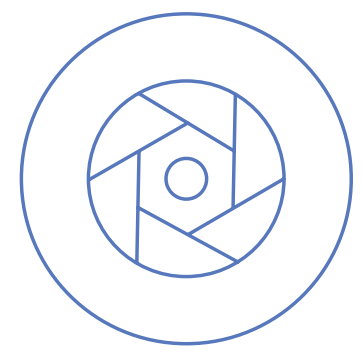

Biological systems are broadly malleable very early in life, and as the organism matures, these systems become settled in form and function and become less vulnerable to environmental insult

Ann Nutr Metab

\title{
Critical and Sensitive Periods in Development and Nutrition
}

\section{John Colombo et al.}

Key Insight

The concept of "critical" or "sensitive periods" has been known

in developmental science for more than a century and has held special relevance for studies on brain plasticity. This notion of critical/sensitive periods in developmental sciences has been widely invoked in the context of the concept of nutritional programming: the prenatal period is a time when various metabolic systems are malleable and can be influenced by conditions of maternal physiology and environmental exposures, including nutrient intake. Currently, the term "sensitive period" is used to refer to these early periods of malleability. Nevertheless, it is very difficult to conclusively establish sensitive periods for particular nutrients.

\section{Current knowledge}

Some of the earliest data arose from observing the effects of toxic substances on embryos. Toxic exposures occurring during the embryonic period had severe effects across multiple systems; interestingly, the same exposure later in development resulted in milder and more restricted effects. Behavioral studies on imprinting in birds not only reinforced the concept of the critical period, but emphasized several key points. First, there was a brief period of great learning plasticity, during which imprinting could occur. Second, exposure during this critical period was largely irreversible. We now understand that some degree of recovery is possible under special conditions. These concepts have been extended across different fields, including language, food imprinting, and nutritional programming.

karger@karger.com

(c) 2020 S. Karger AG, Basel

www.karger.com/anm

\section{Karger $\stackrel{2}{\circ}$}

\begin{tabular}{l|l|c}
\cline { 2 - 3 } Goal & Barriers & Solutions \\
$\begin{array}{ll}\text { Understand } \\
\text { the role of }\end{array}$ & $\square$ Ethics & $\square$ Demonstrating efficacy \\
specific & $\square$ Different demographics & Meta-analyses of \\
nutrients & in study populations & $\begin{array}{c}\text { Focus on timing of } \\
\text { interventions }\end{array}$ \\
$\begin{array}{l}\text { and their } \\
\text { sensitive } \\
\text { period(s) }\end{array}$ & $\square$ Different doses, timings & $\square$ Alignment of \\
& $\square$ Different outcomes & outcomes
\end{tabular}

Overcoming the barriers to understanding the role of micronutrients and the sensitive period.

\section{Practical implications}

How can we determine the sensitive period for a specific nutrient (i.e., a particular vitamin or micronutrient) in human development? Future trials must not only overcome the hurdles of ethics but also face the great challenge of demonstrating efficacy for isolated nutrients within a complex system. One way to overcome this is to insist that meta-analyses of those trials include the age group of their interventions and where outcomes are comparable. Comparison of the DIAMOND and KUDOS trials provides a starting point for such efforts. Although the comparisons cannot be considered definitive, this paves the way for future trials to harmonize outcomes and brings us one step closer to understanding whether the effects of nutrition are mediated by sensitive periods of human development.

\section{Recommended reading}

Colombo J, Carlson SE, Cheatham CL, Shaddy DJ, Kerling EH, Thodosoff JM, et al. Long-term effects of LCPUFA supplementation on childhood cognitive outcomes. Am J Clin Nutr. 2013 Aug:98(2):403-12. 